\title{
Sustaining SMEs Competitive Advantage: How Significant is the Role of Service Provider
}

\author{
Norudin Mansor
}

\author{
Siti Haryati Shaikh Ali
}

Jamilah Sabri

Universiti Teknologi MARA; *Email: norudinm@tganu.uitm.edu.my

\author{
Doi:10.5901/mjss.2015.v6n5s2p579
}

\section{Abstract}

\begin{abstract}
The exploration and discussion of this paper are expected to provide an understanding of the relationship between the service provider roles towards sustaining entrepreneurial competitive advantage among the Small Medium Enterprises (SMEs) in the state of Terengganu. The paper further expected to generate certain degree of generalization of the SMEs operators from the investigation through the use of quota sampling, where 260 respondents were selected from seven (7) districts. The three (3) independent variables concerning capital, knowledge and promotion were used for testing the relationship towards sustaining entrepreneurial competitive advantage. For the purpose of elucidating the data from respondents, closed-ended question was formulated. The question was divided into $A, B$ and $C$ where each section contained 11,12 and 29 respectively. The finding of the study revealed that all the selected predictors found to be significantly correlated with the strategies of sustaining entrepreneurial competitive advantage. One of the interesting evidence which highlighted in this study centers on the need to address the importance of designing different strategies that can strengthen the competitive advantage of the SMEs based on gender and the age category of the business operators.
\end{abstract}

Keywords: entrepreneurship; capital; knowledge; promotion; competitive advantage;

\section{Introduction}

The multifold contributions of entrepreneurship have emerged to be the most potential economic forces that are shaping the world's economy and it further indicate the level of international competitiveness. The importance of entrepreneurship comes from its presence in terms of the number of its establishment, its contribution towards employment, and the generation of new ideas to improve the business deliveries. Similarly, the concept of entrepreneurship has been acknowledged as one of the important components that continuously supports the economic development of Malaysia (Norudin, 2014) where more than $80 \%$ of the business activities involved the participation of the Small Medium Enterprises (SME). The strengthening of SMEs contributions may not be significant without the support of government through several agencies like Urban Development Authority (UDA), Ministry of Trade and Industries (MITI), Malaysian Trade and Industries (MATRADE) and other special agencies like Majlis Amanah Rakyat (MARA), TEKUN and a few others. This study attempts to elucidate the facilities provided by MARA as to what extent it can enhance people to be an entrepreneur. Entrepreneurs are a person who organizes and operates a business or business activities and taking on financial risk. Likewise, they take responsibility for any failure that may befall their businesses. The entrepreneur is usually a sole-proprietor, partner, or the one who owns the majority of shares in an incorporated venture. Entrepreneurs are catalysts for economic change, and researchers argue that entrepreneurs are highly creative individuals with a tendency to imagine new solutions by finding opportunities for profit or reward. Among the business ventures that are normally associated with entrepreneurs are manufacturing activities, whole selling, retailing, information technology and several other services related activities.

Although continuous attempts had been initiated by government and non-governmental institutions in moulding the spirit of entrepreneurs, but still a small fraction of the population has the courage and confidence to venture into this career. This could be due to unresolved issues like inadequate capital, inability to acquire efficient equipment and facilities, slow rate of new technology adoption, low skills and lack of proper guidance. The observation of these scenarios found to be very common, especially among the Bumiputera entrepreneurs throughout the nation. Moreover, most of the business operators in the state of Terengganu found to have little exposure in terms of knowledges and proper linkages in approaching the respective agents or authorities in producing proper documents that are related with 
the directions towards venturing into entrepreneurship. With the national objective of attempting to balance the entrepreneurial activities in Malaysia, Malay for Indigenous People's Trust Council (MARA) was set up as one of the statutory bodies to assist SMEs operators by providing various facilities such as capital financing, strengthening skills and knowledges, financing of equipment and facilities, human resource training and marketing. With the policy of helping entrepreneurs within the SMEs categories, MARA has been instructed by the government to provide a maximum loan amounted to be up to RM 500, 000 based on the service charges of $4 \%$ per annum.

In an effort to provide an efficient support service, the government continuously upgrading the capabilities of MARA as one of the government's arm. It ensuring that all state officers as well as district officers throughout the nation being upgraded in terms of their knowledge and skills, thus placing them into better salary scheme. They are given the authority and responsibility to actively undertake the role of providing various forms of training and mentoring program for Bumiputera. With the assigned responsibilities, the trainers from MARA are expected to help the SMEs to equip themselves with knowledge, skills and shaping the right attitude so as to remain viable, competitive and successful in managing their business operation. The effort of enhancing and strengthening SMEs is evidenced through the set-up of several jointly organized efforts by the Entrepreneur Development Ministry and collaboration with other government agencies as well non-governmental organizations. With this collaboration, the activities covers the entrepreneurship training courses, advance training modules, seminars, workshops that are expected to generate new exposures, the frontiers of knowledge and upgrading of potentials that can be built up into becoming a new entrepreneurial culture.

\subsection{Problem statement}

Evidence from past literatures revealed that there was a steady increase in the birth rate as well as the death rate throughout various businesses in most countries of the world as well as in Malaysia. Thus the need to observe sustaining competitive advantage within entrepreneurship, career is highly essential in ensuring that the wealth of the societies and nation remain intact. In an attempt to accomplish the competitive advantage, it is therefore necessary for the business is to have adequate capital, the need to develop linkages, enhancing the skills and knowledge of the business, as well as utilize the right and efficient facilities in operating day to day business operation. As suggested by Shaikh Ali and Norudin (2012), evidence from previous studies indicated that some of the threats in entrepreneurship venturing in Malaysia are inadequate capital, poor linkages, lack of facilities and improper personal entrepreneurship traits attached to the entrepreneurs (Norudin et al., 2011).

Referring to the discussion with several senior officers from MARA, it was reported that most of the business operators in the state of Terengganu found to be inadequate in terms of knowledge and linkages about the agents or authorities that are readily available in providing support and assistance to them, so that they will continuously survive and competitively manage their businesses. For some operators, although they had been quite long in the business, but still some of them had a poor communication skills and still adopting the less professional approach in marketing their product and services. What more if someone new in the industry attempting to be one of the players in a more challenging and fierce competition. Obviously, it requires certain basic skills to meet the challenges in recognizing the market need. Meanwhile, there is also a need to upgrade strategically the changing stages of the business development. Sometimes, the promotional efforts were not seriously considered as it seems to be an expensive effort due to the unaffordable cost of advertising.

Meanwhile, the need to understand certain major differences among the entrepreneurs still very relevant if any of the related institutions are to be given responsibilities to assist the entrepreneurs. This is due to the fact that, for example the way assistance needs to be tailored will be different when taking into consideration the element of gender, type of business and years of entrepreneurial experience. Having the same generic strategies may possibly may end up helping one group but not the other groups.

\subsection{Scope of study}

This study focused on relationship of facilities provided by MARA and certain other attributes of the entrepreneurs towards sustaining competitive advantage in the industry in the state of Terengganu. In terms of the units of analysis, the investigation focused on the entrepreneurs in the state of Terengganu which had received financial assistance and services provided from MARA. All data were collected from the entrepreneur by using the personally administered questionnaires. In getting the more relevant insight, only one (1) dependent variables which are sustaining entrepreneurial competitive advantage and four (3) independent variables which are capitals, knowledge and promotion involved. The relationships of the variables is being depicted in the research framework. 


\section{Literature Review}

We view an entrepreneur as a person who is willing and able to convert a new idea or invention of products or services into a successful innovation (Schumpeter, 1934). For anyone that is willing to embark into entrepreneurship, he should assume to take the financial risk of starting and operating the business venture. He usually carries the connotation of being creative, self-motivated, and visionary. Based on the Islamic Tasawwur concept, entrepreneurship is one of the best occupations in the world. Muslim scholars like Al-Qardawi (2007) states that Muslim are called to pursue and persevere in entrepreneurship activities. Al-Masri (2007) explains the Hadith place the highest recognition on the businessmen with the Prophets, 'siddiqin and al-Shuhada' during the judgement day. Parallel to the growth of entrepreneurships, the needs for entrepreneurship educations become apparent especially for a developing nation like Malaysia (Norudin et al, 2011). That evidence is truly an encouragement for people to become an entrepreneur. Entrepreneurship is the process of the creating something new with value through running the business by promoting the time, effort, ideas, emotional and capital to gaining the worth. According to the remarks by Stoner and Fry (1982), some of the people became entrepreneur due to the dissatisfaction with the previous job. These reflect that, entrepreneurship is getting wider attention recently with increasing globalization and also the saturation of the job market due to the recent downturn in the various economies of the world. While Copper (1993) said that the factor behind the involvement of someone into entrepreneurship was due to the need to improve the quality of living, to continue day to day life activities within moderate economic climate and migrating from urban to rural development. Thus, the entrepreneur must find, evaluate and develop an opportunity by overcoming the forces that hinder the creation of something new. The whole process starts with identification and evaluation of the opportunity, development of the business plan, followed by determination of the require resources. The final phase involves the management of the resulting enterprise (Norudin et al., 2011).

Having discussed the definition and role of an entrepreneur, we realize the need for him or her to sustain the business competitive advantage. In doing so, this research intends to study a number of factors affecting the process of sustaining business competitive advantage (as outlined below). Those factors include capital, knowledge and promotion.

\subsection{Sustaining competitive advantage}

The success of a competitive advantage firm can be observed through objective and subjective measurement. Objective criteria include return on investment, market share, profit and sales revenue, while subjective criteria may include reputation with customers, supplier and competitors and improving the products and services (Barney, 2002). One of the clearest indicators of the competitive advantage involved product differentiation is quickly identifiable by entrepreneurs. Due to that, entrepreneur should continuously develop the new products and organizational abilities. Competitive advantage means providing advantage over the competitors by offering consumers greater value either through lower price or by providing more benefits that justify the higher price (Kotler \& Armstrong, 2010), and thus allowing them to achieve market share and profitability. Competitiveness also defined as the ability of firms to design, produce and or market products superior to those offered by competitors, considering the price and non-price qualities (Dyer et al., 1998). Cristensen (2010) defines the competitive advantage as possessing whatever value a business can provide that motivates its customers to purchase its product and services rather than those of its competitors. Two different things are apparent in the business venture; one is the encouragement to be involved in the business, and second is to maintain the business. One of the ways of continuing surviving in this area is by promoting and maintaining its competitive advantage (Shaikh Ali et al., 2012). Reality may not be easy as it may sound where in certain business such as communication gadgets or food industries, the competitors are always taking advantage to grab the opportunity based on their serious research for their products and services. With the collaborated effort taken by MARA, other government agencies, private and non-governmental organizations (NGOs) several initiatives have been taken by providing the financial loan, tangible capital such as machineries and also the setting up the development courses to enable entrepreneurs to acquire knowledge and improving their skill. These initiatives may provide avenues for entrepreneurs to compete within local, national, as well as international markets.

In developing the framework, the following dimensions are suspected to be the possible independent variables affecting sustainability competitive advantage.

\subsection{Capital}

Financial capital is one of the most important elements to start the business and growth of the business. Lack of the 
financial training is the most critical problem during the start-up stage, even after the business venture been established (Amatucci \& Crawley, 2011; Siti Haryati et al., 2004). Nguyen et al. (2004) believes that inadequate knowledge of financial management is the main reason behind the high level of business failure. Based on the statement, it is shown that the financial management training is important to the entrepreneur, as the outcome will eventually strengthen the financial strategy of the entrepreneur. With a proper planned and well executed financial strategy, it will provide a proper investment decision and financing decision. Based on the Neuberger and Rathke (2009), the additional sources of capital like loan for the financial or government institution in the country is also required to run the business. MARA is one of the government sectors that provide the financial services to the infant and existing entrepreneur in Malaysia. There are some categories of financing that had been provided by MARA. Among others such as UK Dynamic loan for a loan below than RM 10,000, AM loan for more than RM 10, 000 up to RM 200, 000 and Contract Loan for a loan more than RM 200,000 . Financing by MARA does not involve any element of "riba" as the mechanism of charging on the principal followed the Islamic financial concept. In addition, MARA also provides the accounting capital which is the tangible capital such as machinery to the entrepreneur. Besides, MARA also provides the financial management training to the entrepreneur to make sure they will use the capital wisely.

\subsection{Knowledge}

Knowledge is the factor in which entrepreneurs can differentiate themselves from their competitors. Knowledge will transform the poorly organized business to a well organize business, complex manageable world and the unclear item to be interpreted item. This means the capacity of knowledge can solve the complicated problem that will be encountered by the business venture. Dougherty (1999) describes that knowledge comes as a person who used information and combine it with their personal experience. Besides, knowledge that gathers by the person has their own value. The discovery by Drucker (1993) revealed that knowledge act as the important resources for the individual firm, enterprise or businesses and the key driver of competitive advantage for the nation in the world in order to compete with other competitors. It is more relevant to have a knowledge strategy that is well understood by all people. This will enable individuals to understand their roles and what they need to do next (Uit Beijerse, 2000). It means to affirm that, a well organize knowledge strategy is needed to make sure the input that need to be delivered to the entrepreneur is delivered. This socalled "exploitation" was related to the study which have done by MARA through its Entrepreneur Development Training which is known as LPU (Latihan Pembangunan Usahawan). It also known as the organizing courses enabling the Bumiputera entrepreneur to start a business trade. LPU is also being made available for existing entrepreneur, in order to ensure the entrepreneur in Terengganu continuously acquiring new knowledge and skills of the business venture and developed the competitive advantage for himself of herself and also enhancing the efficiency of their production. All courses provided by MARA is useful for the entrepreneur. As suggested by Birley et al. (1987), even they willingly to be in the business, but they need other enabling devices such as attending training programs that may assist them to put their ideas into effects.

\subsection{Promotion}

Promotion is communicating with the public in an attempt to influence them toward buying your products and services. Based on the American Marketing Association (AMA), sales promotion is the use of media and non-media marketing pressure applied for a predetermined, limited period of time in order to stimulate trial, increase the consumer demand or improves the product quality. In other hand, effective sales promotion also increases the basic value of a product for a limited time and directly stimulates consumer purchasing, selling effectiveness or the effort of the sales force. It can be used to inform, persuade, and remind target customers about the business and its marketing mix. Sales promotion also acts as a competitive weapon by providing an extra incentive for the target audience to purchase or support one brand over another (Faitira et al., 2012). Sales promotion has become vital and grown substantially over the years. The dramatic growth in sales promotion becomes essentially relevant due to several reasons. First, consumers have evaluated sales promotion as part of their purchasing decision criteria. It provides some degree of justification to the reluctant decision makers to make choices on the extra value offered by a particular brand. Second, the increasing tendency of businesses to focus on short-term business strategy and goal attainment provides an immediate boost in sales. Besides, buyers may learn about price discounts at the point of sale whereby price reductions may be posted on the package, promotion banners, on signs near the displayed product, or even at the storefront windows, besides using fliers, newspaper and television ads. Price discounts may be initiated by the manufacturer, wholesaler, retailer or the distributor. Strategically well planned promotion effort may start with effort such as a manufacturer may "pre-price" a 
product and then obtain the commitment of retailer to participate in the discount campaign through extra incentives. Most of the existing customers perceive discounts as rewards and some may increase their respond by buying in larger quantities. Price discounts alone may not be able to induce first time buyers (Kotler \& Keller, 2006), unless it can be associated with other elements like quality, reliability and other justifications.

\section{Research Methodology}

\subsection{Research design}

This correlation investigation emphasized on gathering primary data cross-sectionally. The identification of the variables for the investigation started with the observation of the cases, followed by interviewing a few key personnel, reviewing of past literatures and precisely formulating a research framework which acts as the main theme of the research process. In ensuring data that had been collected will be free from misleading responses, the procedures of self-administered questionnaire was strictly followed. The collected data went through a rigorous pilot testing procedure and analyzed statistically to arrive at the conclusion and recommendation phase. The approach taken in this investigation went through the reliability procedures, and data were further explored and tested in terms of observing its relationship between the selected independent variables and the dependent variable. Further analysis was conducted for examining the possibilities of differences on the entrepreneurial competitive advantage based on certain selected demographic profiles.

\subsection{Instrumentation and data collection}

Although there were agencies geared to provide similar assistance, the empirical data only focus on selected entrepreneur that had obtained the financial support from MARA in every district in the state of Terengganu. Knowing the area of their business location, we decided to adopt a quota sampling approach with the interest of obtaining a certain degree of generalization for the population in this study. About 300 questionnaires were distributed on a quota sampling approach, whereby only 260 of the total successfully responded. There were 60 items formulated for exploring the information from the respondents that are selected quotably. The questionnaire consists of four sections. Section A attempted to capture data on the respondent's background such as gender, age, educational level, marital status, monthly income, business capital, years of experience, district, sector and the involvement on these systems. Section B focused on the sustaining the competitive advantage. Items related to the roles of service (section $\mathrm{C}$ ) were further classified into three subsections representing capital, knowledge and promotion respectively. The proposed framework for this study is shown in Figure 1.

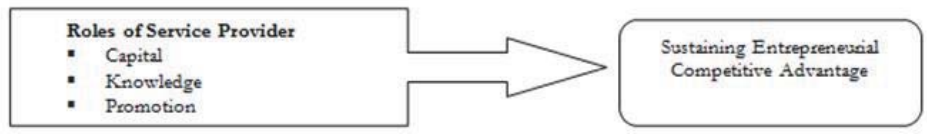

Figure 1. Theoretical Framework of Variables Relationship

\subsection{Research hypotheses}

With the framework introduced, the following are the proposed hypotheses:

$\mathrm{HI}(\mathrm{A})$ : There is a significant relationship between accessibility of capital with sustaining entrepreneurial competitive advantage

$\mathrm{HI}(\mathrm{B})$ : There is a significant relationship between the acquisition of knowledge with sustaining entrepreneurial competitive advantage

$\mathrm{HI}(\mathrm{C})$ : There is a significant relationship between promotional efforts with sustaining entrepreneurial competitive advantage.

H2: All the selected independent variables (accessibility of capital, acquisition of knowledge, promotional efforts) are able to explain the sustaining entrepreneurial competitive advantage.

H3 (Ai): There are perceptual differences between the respondents' gender and accessibility of capital.

H3 (Aii): There are perceptual differences between the respondents' gender and acquisition of knowledge. 
H3 (Aiii): There are perceptual differences between the respondents' gender and promotional efforts.

$\mathrm{H} 3$ (Bi): There are perceptual differences between the age and accessibility of capital.

H3 (Bii): There are perceptual differences between the age and the acquisition of knowledge.

H3 (Biii): There are perceptual differences between the age and promotional efforts.

H3 (Ci): There are perceptual differences between the respondents' years of the entrepreneurial experience and accessibility of capital.

H3 (Cii): There are perceptual differences between the respondents' years of the entrepreneurial experience and acquisition of knowledge.

H3 (Ciii): There are perceptual differences between the respondents' years of the entrepreneurial experience and promotional efforts.

H3 (Di): There are perceptual differences between the respondents' type of sectors and the accessibility of capital.

H3 (Dii): There are perceptual differences between the respondents' type of sectors and the acquisition of knowledge.

H3 (Diii): There are perceptual differences between the respondents' type of sectors and the promotional efforts.

\subsection{Sampling design}

The study was conducted in the state of Terengganu covering the entrepreneurs that had obtained the financial and nonfinancial support from MARA. Based on the Target and Achievement Report listed by the MARA state office of Terengganu for the year 2013, there were 626 borrowers actively involved in the businesses. The researcher used the quota sampling technique in order to get the most efficient representation of the population. The researcher decides to divide the 260 respondents into seven different districts which are Besut, Setiu, Kuala Terengganu, Hulu Terengganu, Marang, Dungun and Kemaman. It is recommended by Krecjie and Morgan (1970) that with the above total populations, the suggested sample size would be 274 . However, after several attempts to get their participation, only 260 samples appropriately considered. From the total population, the largest populations were from Kuala Trengganu followed by Dungun and Besut which were 176, 130 and 95 of entrepreneur respectively. Next is Setiu, Hulu Terengganu and Marang which were 76,57 and 55 of entrepreneur respectively. Whereas, the smallest group is represented by Kemaman with the total of 37 entrepreneurs.

Table 1. Table of Population

\begin{tabular}{|lccccc|}
\hline District & Population & Sample & District & Population & Sample \\
\hline Besut & 95 & 22 & Marang & 55 & 29 \\
Setiu & 76 & 29 & Dungun & 130 & 15 \\
Kuala Terengganu & 176 & 116 & Kemaman & 37 & 28 \\
Hulu Terengganu & 57 & 21 & & & \\
\hline
\end{tabular}

Total population 626; total sample 260

\section{Findings and Discussion}

Several interim analyses through testing of normality and reliability were performed before conducting the related analyzing procedure in response to the formulated research objective and hypotheses.

\subsection{Normality and reliability analysis}

Based on testing of normality the finding revealed that the value of competitive advantage, Capital, Knowledge and Promotion, were closed to normal and with 260 samples normality of data is assumed. Another interim procedure of reliability analysis was once again performed as been done during the pilot testing of the research project. The finding initially suggested that some of the items need to be dropped for ensuring reliability of the data is acceptable. After several adjustments were made, all the variable concerning Sustainable Competitive Advantage, Capital, Knowledge and Promotion justified being reliable with the alpha value of $0.884,0.801,0.832$ and 0.799 as shown in Table 2 . 
Table 2. Reliability Analysis

\begin{tabular}{|lcccc|}
\hline \multirow{2}{*}{ Section } & \multicolumn{2}{c}{ Before Adjusted } & \multicolumn{2}{c|}{ After Adjusted } \\
& Items & Alpha Value & Items & Alpha Value \\
\hline Sustain Competitive Advantage & 17 & 0.881 & 15 & 0.884 \\
Capital & 12 & 0.788 & 10 & 0.801 \\
Knowledge & 7 & 0.781 & 6 & 0.832 \\
Promotion & 8 & 0.733 & 7 & 0.799 \\
\hline
\end{tabular}

\subsection{Distribution of sample profiles}

The summary of sample profile can be observed in the attached Table 3. From total respondents, about $44.6 \%$ were those from Kuala Terengganu, 11.2\% from Setiu, 8.5\% from Besut, 10.8\% from Kemaman, 8.17\% from Hulu Terengganu and $5.8 \%$ were those representing Dungun. The breakdown of gender composition displayed that $35 \%$ were male, while $65 \%$ were female SMEs operators. In the age group representation, the composition is as follows; $24.2 \%$ is between the age of 21-30 years old, $28.8 \%$ represent the age of 31-40 years old, another $28.9 \%$ show the age between $41-50$ years old, while the rest were those between 20 years old and more than 50 years old.

For the element of income, the highest percentage of income level between RM 1000-RM 1999 was 44.2\%, followed by RM2000-RM2999 (33.1\%), RM 3000-RM4999 (15.0\%), RM 5000-RM 9999 (5.0\%) and the least were those with income level between RM 10000. Referring to the element of the years of experience in business, $38.8 \%$ of them were having experience < 5 years, and $42.7 \%$ of them were 5-10 years which is the highest percentage of years of experience. For $21-29$ years with 30 years and above years of experience give $8.5 \%$ and $10.0 \%$ respectively. The next elements is sectors, there are $45.4 \%$ of the respondents involve in manufacturing sector and followed by services which give $27.7 \%$. There are $18.5 \%$ of them involved in wholeselling, and another $8.5 \%$ involve in trading.

Table 3. Frequency of Respondent's Profile

\begin{tabular}{|l|c|c|l|c|c|}
\hline Questions & Freq. & $\%$ & Questions & Freq. & $\%$ \\
\hline Age & & & & & \\
20 years < & 13 & 5 & Experience as an Entrepreneur & \\
21-30 years & 63 & 24.2 & Less than 5 years & 101 & 38.8 \\
31-40 years & 75 & 28.8 & 5-10 years & 111 & 42.7 \\
41-50 years & 75 & 28.8 & 21-29 years & 22 & 8.5 \\
51 years $>$ & 34 & 13.1 & 30 years and above & 26 & 10.0 \\
\hline Monthly Income & & & & & \\
RM1000-RM1999 & 115 & 44.2 & Sector Involved & \\
RM2000-RM2999 & 86 & 33.1 & Manufacturing & 118 & 45.4 \\
RM3000-RM4999 & 39 & 15.0 & Wholeselling & 48 & 18.5 \\
RM5000-RM9999 & 13 & 5.0 & Trading & 22 & 8.5 \\
RM10, 000 and above & 7 & 2.7 & Service & 72 & 27.7 \\
\hline
\end{tabular}

\subsection{Correlation analysis}

The reviewing of the past literature pointed out the importance of capital, knowledge, and promotion as among the elements that contribute towards sustaining competitive advantage. Similarly, this paper attempted to access the strength as well as how significant are the relationship among the variables. Following the suggestion by De Vaus (2002), the values in Pearson correlation as depicted in the Table 4 is explained. The analysis of the correlation indicated that there was a moderate relationship of knowledge, low relationship for promotion and low relationship to capital as to sustaining competitive advantage. This can be observed based on the sig. value of $0.501,0.388$ and 0.164 respectively. Element of capital having low to moderate correlation as being displayed by Pearson correlation value of 0.164 , thus indicating that capital is not really able to support the entrepreneur towards sustaining entrepreneurial competitive advantage. Most of the entrepreneurs seem to have difficulties in accessing or acquiring having capital for their businesses. While the elements of promotion having moderate to substantial correlation as being depicted by Pearson correlation value of 0.388, thus indicating that the marketing and promotion efforts by MARA effectively helped the entrepreneurs to sustain the competitive advantage. Nevertheless, all the factors have a significant relationship sustaining entrepreneurial 
competitive advantage based on 0.000 and 0.008 which is shown in Table 4. Hence, H1A, H1B and H1C are substantiated.

Table 4. Pearson Correlation Coefficient for Variables

\begin{tabular}{|l|c|c|c|}
\hline & Capital & Knowledge & Promotion \\
\hline Competitive Advantage & & & \\
Pearson Correlation & $0.164^{\star *}$ & $0.501^{\star *}$ & $0.388^{\star *}$ \\
Sig. (2-tailed) & 0.008 & 0.000 & 0.000 \\
\hline
\end{tabular}

${ }^{*}$ Correlation is significant at the 0.01 level (2-tailed).

\subsection{Multiple regression analysis}

The displayed value in Table 5 provides further justification of the relative importance between the concept of knowledge, promotion and capital in predicting their contribution to sustaining competitive advantage. The displayed value in the coefficient table indicated that knowledge formed the best predictor, followed by promotion as been tabled by the beta value of 0.244 and 0.171 . Both were significant at the significant value of 0.000 .

However, the analysis between capital and sustaining competitive advantage provide a debatable finding as it is not significant through the regression analysis which is not symmetrical as to the finding generated based on Pearson correlation analysis. Meanwhile, the elements of capital show the lowest beta -0.067 which describes the inverse relationship toward sustaining entrepreneurial competitive advantage. Based on our interview with several business operators, the process of obtaining capital is not being made easily available for the entrepreneur in Terengganu. The significant value shows that the combination of the determinants which based on knowledge and promotion has a significant relationship with sustaining the competitive advantage, while the determinant capital is not significant because the value 0.285 which is more than critical value 0.05 . Based on the regression analysis, the exploration further attempt to understand to what extent all the three selected predictors are able to explain their contribution to sustaining competitive advantage. The result indicated these predictors are able to explain $30.8 \%$ of its contribution, while the remaining $69.2 \%$ could be due to other factors that had not been included in this study. Nevertheless, the usefulness of knowledge, capital and promotion are still significant at 0.000 sig. value.

Table 5. Coefficient Table between Investigated Variables

\begin{tabular}{|c|c|c|c|c|c|c|}
\hline $\mathrm{R}$ & $\begin{array}{c}\text { Summary } \\
\text { Adj-R-Square }\end{array}$ & Sig. & Model & $\begin{array}{l}\text { Std. Coefficient } \\
\text { Beta }\end{array}$ & $\mathrm{t}$ & P-Value \\
\hline \multirow{3}{*}{0.556} & \multirow{3}{*}{0.308} & \multirow{3}{*}{0.000} & Capital & -0.067 & -1.071 & 0.285 \\
\hline & & & Knowledge & 0.424 & 7.577 & 0.000 \\
\hline & & & Promotion & 0.269 & 4.080 & 0.000 \\
\hline
\end{tabular}

Dependent Variable: Sustaining Competitive Advantage

\subsection{T-test analysis}

T-test was conducted for gender on roles of service provider based on three dimensions involving Capital, Knowledge, and Promotions. The result of the t-test in Table 6 displayed the difference in the means of 3.4884 and 3.2696. It was significant at 0.018 between the male and female which based on their perception on assessment of capital provide by the service provider. The male counterpart believed that they can access better avenues in obtaining the capital from a service provider. Similarly, the observation on promotion assistance given by the service provider, the male respondents agreed that the promotion given considered found to be more helpful for their businesses as compared to the female samples at the significant value of 0.035 . However, the reviewing of the analysis on the impact of knowledge given by the service provider, the female respondents agreed that they could acquire more knowledge as compared to the male respondents at shown by the significant value of 0.003 . Thus, gender is one of the main issues that needed special attention by the service provider when factors concerning Capital, Knowledge and Promotion were to be included in assisting the entrepreneur. 
Table 6. Table T-test for Gender with Capital, Knowledge and Promotion

\begin{tabular}{|cccccccc|}
\hline & \multicolumn{2}{c}{ Capital } & \multicolumn{2}{c}{ Knowledge } & \multicolumn{2}{c|}{ Promotion } \\
Gender & $N$ & Mean & Sig. & Mean & Sig. & Mean & Sig. \\
\hline Male & 91 & 3.4884 & 0.018 & 4.1777 & 0.003 & 3.9733 & \multirow{2}{*}{0.035} \\
Female & 169 & 3.2696 & & 4.3866 & & 3.8022 & \\
\hline
\end{tabular}

\subsection{Kruskal-Wallis analysis}

For the purpose of this study, the demographic factors selected to be tested and explored were the age of the entrepreneur, years of experience become an entrepreneur and business sectors. This analysis somehow provides some evidence for the understanding of the difference of these profiles had on the role of service provider in terms of capital provided, the knowledge given and promotion assistance in promoting the entrepreneurs.

The result as shown in Table 7 indicated that there are significant difference at 0.030 and 0.033 values for the age group towards capital as well as knowledge given by the service provider to the entrepreneurs. It also indicated that the entrepreneur in the age range of 31-40 years old, 41-50 years old and 51 years above were given more access to the capital. However, only those with the age category of 31-40 years old and 41-50 years old seems to agree the knowledge is useful. Hence, $\mathrm{H3}(\mathrm{Bi})$ and $\mathrm{H} 3$ (Bii) are substantiated. While there is no significant difference between age groups as to promotion, indicating that $\mathrm{H} 3$ (Biii) failed to be supported.

The observation on profiles for years in business (less than 5 years, 5-10 years, 21-29 years, and 30 years and above) indicated that there was a significance difference in the means of $113.37,137.32,140.82$ and 159.56 with significant value of 0.015 . The difference in mean rank of $135.80,140,90,96.09$ and 94.63 as the significant value of 0.004 in relation to capital and knowledge assisted by the service provider. However, the analysis of years in business displayed the result of mean value of $116.52,135.43,141.52$ and 154.42 in relation to promotion assistance offered at the significant value of 0.068 . Thus, the demographic factors between years of becoming entrepreneur towards the sustaining entrepreneurial competitive advantage based on capital and knowledge is significant which supporting $\mathrm{H} 3$ (Bi) and $\mathrm{H} 3$ (Bii). But, the evidence does not support $\mathrm{H} 3$ (Biii) where significant value is greater than the critical value of 0.05 .

With regards to the observation of business sector categories (manufacturing, wholeselling, trading and services) the result indicated the means of 126.57, 154.10, 141.16 and 117.95 which were significant at the value of 0.008 . However, extra attempts need to be considered as there was no significance difference between the business sectors with regards to the knowledge and promotion assistance provided by the service provider as depicted by the significance value of 0.057 and 0.096 respectively. Thus, the demographic factors between sectors towards the sustaining entrepreneurial competitive advantage based on knowledge and promotion is not significant.

Table 7. Kruskal-Wallis for Age, Years in Business and Business Sector

\begin{tabular}{|c|c|c|c|c|c|c|c|}
\hline Profiles & \multirow{2}{*}{ No. } & \multicolumn{2}{|c|}{ Capital } & \multicolumn{2}{|c|}{ Knowledge } & \multicolumn{2}{|c|}{ Promotion } \\
\hline Age & & Mean Rank & Sig. & Mean Rank & Sig. & Mean Rank & Sig. \\
\hline 20 years and below & 13 & 122.73 & \multirow{5}{*}{0.030} & 78.35 & \multirow{5}{*}{0.033} & 137.00 & \multirow{5}{*}{0.191} \\
\hline $21-30$ years & 63 & 106.15 & & 131.63 & & 118.56 & \\
\hline $31-40$ years & 75 & 131.02 & & 141.95 & & 131.26 & \\
\hline $41-50$ years & 75 & 142.77 & & 135.38 & & 126.70 & \\
\hline 51 years and above & 34 & 148.38 & & 112.34 & & 156.84 & \\
\hline \multicolumn{8}{|l|}{ Years in Business } \\
\hline Less than 5 years & 101 & 113.37 & \multirow{4}{*}{0.015} & 135.80 & \multirow{4}{*}{0.004} & 116.52 & \multirow{4}{*}{0.068} \\
\hline 5-10 years & 111 & 137.32 & & 140.90 & & 135.43 & \\
\hline 21-29 years & 22 & 140.41 & & 96.09 & & 141.52 & \\
\hline 30 years and above & 26 & 159.56 & & 94.63 & & 154.42 & \\
\hline \multicolumn{8}{|l|}{ Sectors } \\
\hline Manufacturing & 118 & 126.57 & \multirow{4}{*}{0.008} & 126.21 & \multirow{4}{*}{0.057} & 132.99 & \multirow{4}{*}{0.096} \\
\hline Wholeselling & 48 & 154.10 & & 104.93 & & 148.74 & \\
\hline Trading & 22 & 141.16 & & 144.93 & & 130.34 & \\
\hline Services & 72 & 117.95 & & 150.17 & & 114.31 & \\
\hline
\end{tabular}




\section{Concluding Remarks}

Evidences from the above findings form a clear indication about the strength of the relationship between the three dimensions prescribing the role of service provider toward sustaining competitive advantage of entrepreneurs. The explanatory power of the three predictors at $30.8 \%$ suggested that two of them (knowledge management and promotion) are significant while further exploration need to be executed to investigate the importance of managing capital or financing in promoting competitive strength. The difference in the strength of relationship whereby it is really low between capital management and competitive advantage, low moderate relationship between knowledge management and competitive advantage, and moderate relationship between promotion effort and competitive advantage suggested that more serious effort should be taken to provide training or accessibility to financial support if the nation attempt to develop the significant role of small and medium enterprise in Malaysia. Evidence from previous research by Norudin et al. (2014) and Norudin (2005) repeatedly discuss the role of managing finances for assisting small business to survive remain debatable until today. Similarly, in most situations in Malaysia small businesses are not serious enough to invest in promotional activities as they believed that even with the little promotion effort it is adequate enough to sustain their business momentum. Some operators prefer to have a small margin in their business, especially for those operating in the rural areas.

The fact that the willingness to put more effort in managing capital indicated a significant difference in this study. It provides evidence that younger entrepreneurs of less experience entrepreneurs found to be less competent in managing capital compared to much older or more experienced entrepreneurs open up further issues to be debated. For the novice entrepreneurs attempt should be initiated and seriously taken to assist and monitor them in managing capital as well as other dimensions. Failure to do so will eventually repeated earlier weaknesses where the failure rate of doing business found to be high at the early stage of doing business (Bannock \& Albach, 1991).

The need to sustain the competitive advantage and ensuring the business survival in Malaysian industries are vital if the government wishes to achieve the strategic goal of becoming a developed nation by 2020. Obviously, most related parties should be made aware that there have been always a strong linkage between small businesses, medium size enterprises and multinational corporations as the chain of complimenting each others are unavoidable. The evidences which displayed by this paper especially the enhancement of the relationship between capital, knowledge and promotion strongly suggest they need for sustaining the entrepreneurial competitive advantage (Norudin et al., 2011) in promoting Malaysian economy to a much greater height as well gearing the nation to compete in the global market.

The regression model through the R-square value revealed that only $30 \%$ of the service provider dimensions provided the explanation of its explanatory predictive power on sustaining competitive advantage among the entrepreneurs in this study. Although it seems to be logical, further investigation in terms of selecting other variables like changes in social and economic climate, technological adaptation and other psychographic variables which are expected to demonstrate their impact on sustaining the competitive advantage. With the new evidence in the next study, it will provide a new frontier to justify the importance of building and enhancing the productivity of small business entrepreneurs in serving the nation.

\section{References}

Al-Misri, R. Y. A. M. (2007). Al-iqtisad wa al-akhlaq.

Al-Qaradawi, Y. (2007). Al-Halal wa-al-haram fi al-Islam (The lawful and the prohibited in Islam). Beirut: Al-Qahirah: Maktabat Wahbah.

Amattuci, F. M., \& Crawley, D. C. (2011). Financial self-efficacy among women entrepreneurs. International Journal of Gender and Enterpreneurship, 3, 23-37.

Bannock, G., \& Albach, H. (1991). Small business policy in Europe: Britain, Germany and the European Commission. Great Britain: Anglo German Foundation.

Barney, J. (2002). Gaining and sustaining competitive advantage. (2nd ed.) Upper Saddle River, NJ: Prentice Hall.

Birley, S., Moss, C., \& Saunders, P. (1987). Do women entrepreneurs requires different training? American Journal of Small Business, $12,27-36$.

Cooper. A. C. (1993). Challenges in predicting new firm performance. Journal of Business Venturing, 8, 241-253.

Cristensen, H. K. (2010). Defining customer value as the driver of competitive advantage. Strategy and Leadership, 38, 20-25.

De Vaus, D. (2002). Analyzing social science data. Great Britain: SAGE Publication.

Dougherty, V. (1999). Knowledge is about people, not databases. Industrial and Commercial Training, 3, 262-266.

Drucker, P. F. (1993). Post-capitalist society. Oxford: Buttterworth-Heinemann.

Dyer, J. H., Cho, D. S., \& Chu, W. (1998). Strategic supplier segmentation: The next "best practice" in supplier chain management. California Management Review, 40, 57-77.

Faitira, M., Gwangwawa, E., \& Gutu, K. (2012). Sales promotion as a critical component of a small business marketing strategy. 
Interdisciplinary Journal of Contemporary Research in Business, 4, 1157-1169.

Kotler, P., \& Armstrong, G. (2010). Principles of marketing. Pearson Education.

Kotler, P., \& Keller, K. L. (2006). Marketing management. (12th ed.). India: Pearson Education Pic Ltd.

Krejcie, R., \& Morgan, D. (1970). Determining sample size for research activities. Educational and Psychological Measurement, 3, 607610.

Neuberger, D., \& Rathke, S. (2009). Microenterprises and multiple bank relationships: The cases of professionals. Small Business Economics, 32, 207-229.

Nguyen, L. D., Ogunlana, S. O., \& Lan, D. T. X. (2004). A study on project success factors in large construction projects in Vietnam. Journal of Engineering Construction and Architectural Management, 11, 404-413.

Norudin, M. (2005). Woman in business: Determinants for venturing in Malaysians SMEs. In Proceeding of International Conference on Small and medium Size Enterprises in European Economies and All Over the World, Clujj-Napoca, Romania.

Norudin, M., Shaikh Ali, S. H., Ghani, N. A. A. (2011). Entrepreneurial intention: Does Malaysian secondary school provide the platform? Interdisciplinary Journal of Contemporary Research in Business, 1, 19-35.

Norudin, M., Abdullah, Z., Abidin, M. A. Z. (2014). Sustaining competitive advantage of Malaysian construction industry. Journal of Applied Environmental and Biological Sciences, 4, 61-72.

Schumpeter, J. A. (1934). The theory and economic development. Cambridge: Harvard University Press MA.

Shaikh Ali, S. H., \& Norudin, M. (2012). Empirical analysis of competitive advantage of Muslim contractor in the east coast of Malaysia. European Journal of Business and Management, 4, 28-36.

Shaikh Ali, S. H., Norudin, M., \& Ahmad, N. (2004). Factors that motivate women to be entrepreneur. In Third International Conference on SMEs in a Global Economy, UiTM and University Wollongong, Malaysia.

Stoner, C. R., \& Fry, F. L. (1982). The entrepreneurial decision: dissatisfaction or opportunity? Journal of Small Business Management, 20, 39-44.

Uit Beijerse, R. P. (2000). Knowledge management in small and medium-sized companies: Knowledge management for entrepreneurs. Journal of knowledge management, 4, 162-179. 